\title{
The ALIVE Program: Developing a Web-Based Professional Development Program for Nursing Leaders in the Home Healthcare Sector
}

Sara Lankshear, RN, PhD(c)

Relevé Consulting Services

Sherri Huckstep, RN, BScN, MPA

Executive Director Operations and Chief of Practice

VON Canada

Nancy LeFebre, RN, BScN, MScN

Chief Clinical Executive, Senior VP Knowledge and Practice

Saint Elizabeth Health Care

Janis Leiterman, RN, BScN, MPA, CCHN(c)

Director, Chronic Disease Prevention and Management

VON Canada

Deborah Simon, RN, BA (Admin), MBA

Vice-President, Clinical Services

VHA Home HealthCare

\begin{abstract}
Home healthcare nurses often work in isolation and rarely have the opportunity to meet or congregate in one location. As a result, nurse leaders must possess unique leadership skills to supervise and manage a dispersed employee base from a distance. The nature of this dispersed workforce creates an additional challenge in the ability to identify future leaders, facilitate leadership capacity, and enhance skill development to prepare them for future leadership positions. The ALIVE (Actively Leading In Virtual Environments) web-based program was developed to meet the needs of leaders working in virtual environments such as the home healthcare sector. The program, developed through a partnership of three home healthcare agencies,
\end{abstract}


used nursing leaders as content experts to guide program development and as participants in the pilot. Evaluation findings include the identification of key competencies for nursing leaders in the home healthcare sector, development of program learning objectives and participant feedback regarding program content and delivery.

\section{Background}

Recruiting and retaining nursing staff in the home healthcare sector is a challenge shared by all community-based organizations, particularly with regard to current and future leaders. Due to the nature of the care provided, the diverse practice settings and scheduling challenges, home healthcare nurses work in a high degree of isolation and rarely have the opportunity to meet or congregate in one location. To supervise and manage such a dispersed employee base from a distance, nursing leaders must possess unique leadership skills. Hood and Smith (1994) describe nursing leaders as the role most influential in affecting areas such as productivity, staff satisfaction and patient outcomes. Despite the limited face-to-face interaction with staff, nursing leaders have the ability (and responsibility) to make an impact on staff satisfaction (Smith 1997). Strong and accessible nursing leadership is included in the characteristics of "magnet" hospitals - those with the ability to recruit and retain nurses (Kramer and Schmalenberg 1988a, 1988b). Fraser (2003) describes the importance of magnet characteristics to the home healthcare sector as due to the projected increases in provision of care in the community and the need to recruit and retain nurses to meet those client needs. Home healthcare sector literature also describes the importance of competent and supportive managers who are knowledgeable about the community, enable autonomous practice, and provide feedback and coaching (Armstrong-Stassen and Cameron 2005; Flynn and Deatrick 2003; Smith-Stoner 2004).

When considering the relatively short tenure of those in leadership positions, retaining current nursing leaders is vital to ongoing organizational success. Mackoff and Triolo (2008) suggest that focusing on a model of engagement of current nurse managers, rather than on retention, will potentially increase the tenure of those in leadership positions.

A variety of factors make recruiting and retaining nurse leaders in the home healthcare sector particularly challenging. They include the workforce shortages and wage disparity between sectors (i.e., acute care and community sectors). A qualitative study of hospital nurses transitioning to the community sector reported feelings of being alone and not being sure of what to do (Zurmehly 2007). Although the focus of this study was nurses in clinical practice, these comments are often expressed by nurse leaders who are new to the community sector. 
Insufficient investment in ongoing professional development of nursing leaders can lead to feelings of being ill-prepared to meet the diverse areas of accountability associated with their role, ultimately having an impact on organizational effectiveness (O'Neil et al. 2008). By investing in nursing leaders and enabling them to provide strong, accessible leadership to their staff, we not only improve the retention of our current nursing leaders, but we also enhance the development of a cohort of future nursing leaders (Mackoff and Triolo 2008).

The goal of the ALIVE Nursing Leadership Model (Actively Leading In Virtual Environments) is to create a transformational leadership model that addresses the unique needs of nursing leaders in the home healthcare sector. For the purposes of this project, nursing leaders were defined as nurses in formal leadership or management positions, at the point of care, with direct accountability for clinical nurses providing direct client care. The project objectives are to assess educational gaps of current and future home healthcare nurse managers and develop evidence-based resources to assist them in becoming more effective in leadership roles in working with an extremely mobile, dispersed and often isolated nursing workforce.

\section{A Unique Partnership}

The ALIVE Nursing Leadership Model was created through an innovative partnership between VON Canada, Saint Elizabeth Healthcare and VHA Home HealthCare, all not-for-profit home healthcare providers in Ontario. The Ontario Community Support Association, a non-service organization, provided additional support. In a situation unique to Ontario, home healthcare providers are required to compete for a market share of healthcare (managed competition). Despite the fact that these organizations are in true "competition" with one another for the ability to provide home healthcare services, the common desire to invest in the development and retention of nursing leadership enabled a creative and collaborative approach to program design, implementation, sharing resources and engaging staff from across the province. The ALIVE program development process involved three distinct phases: (1) consulting with content experts, (2) developing the program, pilot testing and evaluation and (3) implementing the web-based ALIVE program modules.

\section{Phase 1: Tapping into Our Own Experts}

A content expert panel of four nursing leaders from each of the partner organizations was brought together to discuss enablers and barriers to being a nursing leader in the home healthcare sector and to identify core competencies for successful leadership. To ensure diversity of experience, selection criteria for the panel included one nurse from each of the following categories:

- New to community nursing, new to a formal leadership role 
- New to community nursing, experience in a formal leadership role(s)

- Experience in community nursing, new to a formal leadership role

- Experience in community nursing, experience in a formal leadership role(s)

Members of the ALIVE advisory group identified and approached nurse leaders in their organization and invited them to participate. Participation was voluntary, and all expenses (time and travel) were covered by the organization.

Activities such as brainstorming, visual imagery and nominal group techniques were used to determine the final list of competencies for nursing leaders. For example, participants were asked to give a visual response to the question, "what is it like to be a nursing leader in the home healthcare sector?" Figures $1 \mathrm{a}$ and $\mathrm{b}$ are examples of the visual representations created. Key messages from the responses included the vast areas of responsibility as well as feelings of being on your own yet realizing there are resources available - but sometimes just out of reach.

The 21 competencies generated were then compared to elements in the literature that describe community nursing job satisfaction and characteristics of manager support, as well as the standards of practice documents from the College of Nurses of Ontario (2002) and the Community Health Nurses Association of Canada (2003). (See Table 1 for the list of competencies identified.) The competencies listed within the categories of skills (e.g., communication, leadership and time management) and attributes (e.g., caring, honest and engaged) are consistent with those described in the literature and professional standards. Participants described the competencies listed under the knowledge category as key to success in the role, based on personal experience in their current nursing leadership role.

\section{Lessons Learned}

- Draw from your leaders. The three participating home care provider organizations have acknowledged the benefit of their front-line nurse managers participating together in the pilot project. The project has forged new relationships, shared learning across organizations and facilitated a collaborative environment that can be problematic in the Ontario home care sector because of the competitive bidding process.

- Focus on sustainability right from the funding is one-time in nature, it is important to determine your internal capacity to maintain the program and ensure that plans for sustainability are developed early on in the process.

- The value of partnering. When resources and costs are shared across the partners involved, the individual impact on each organization is relatively small (e.g., costs shared, internal resources tapped into), thereby creating synergies for sustainability. beginning. With the understanding that 

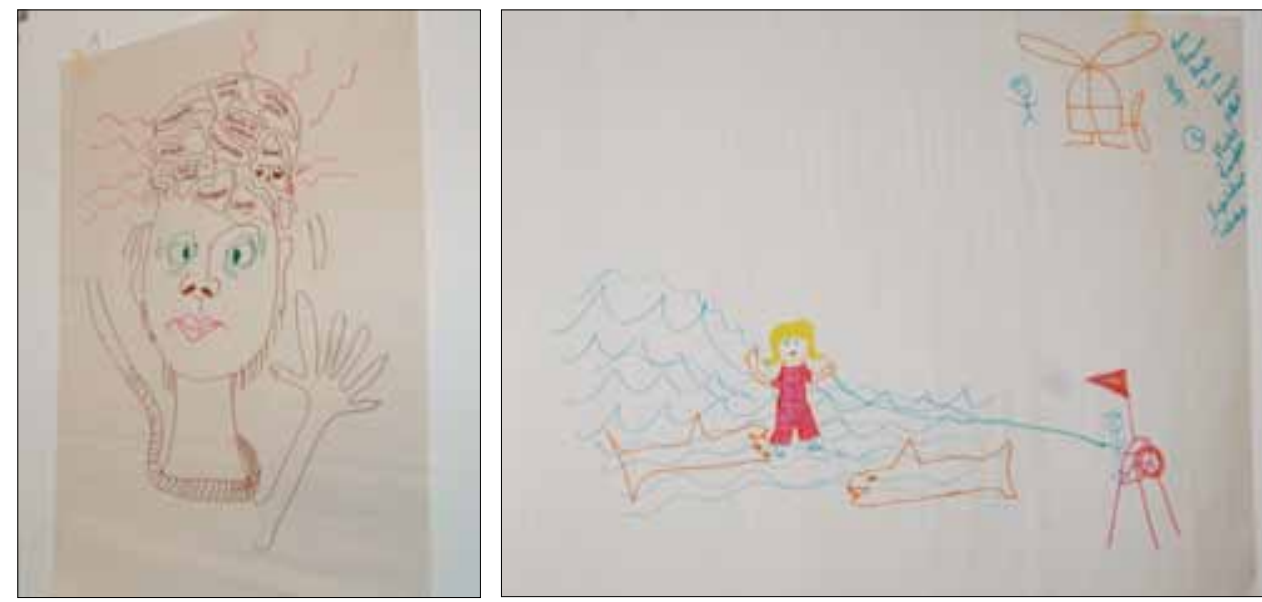

\section{Table 1.}

\section{Key competencies for nursing leaders in home healthcare}

\begin{tabular}{|c|c|c|}
\hline Knowledge & Skills & Attributes \\
\hline $\begin{array}{l}\text { 1. Nursing practice: } \\
\text { understanding best } \\
\text { practices, scope of practice } \\
\text { issues; working with } \\
\text { unregulated care providers } \\
\text { and implications for nurses } \\
\text { 2. Understanding of the } \\
\text { unique issues within the } \\
\text { home healthcare sector: } \\
\text { RFP processes; defining } \\
\text { measures of quality and } \\
\text { determining indicators } \\
\text { to monitor; sound } \\
\text { understanding of the } \\
\text { human resource issues } \\
\text { 3. Managing human } \\
\text { resources: inclusion of } \\
\text { collective agreements; } \\
\text { dealing with performance } \\
\text { issues (i.e., supervising } \\
\text { peers) }\end{array}$ & $\begin{array}{l}\text { 1. Technology: computer skills } \\
\text { 2. Conflict management/ } \\
\text { negotiation } \\
\text { 3. Root cause analysis } \\
\text { 4. Time management: } \\
\text { managing multiple } \\
\text { priorities } \\
\text { 5. Communication skills: } \\
\text { especially when } \\
\text { communication is “virtual” } \\
\text { (i.e., email and/or phone) } \\
\text { 6. Providing constructive } \\
\text { feedback } \\
\text { 7. Leadership skills: ability to } \\
\text { lead, motivate }\end{array}$ & $\begin{array}{l}\text { 1. Enthusiasm } \\
\text { 2. Emotional intelligence } \\
\text { 3. Sense of humour } \\
\text { 4. Caring } \\
\text { 5. Follow-up/follow-through } \\
\text { 6. Honesty } \\
\text { 7. Engaged: being genuinely } \\
\text { present } \\
\text { 8. Consistency, fairness } \\
\text { 9. Adaptable } \\
\text { 10. Takes initiative, is } \\
\text { innovative } \\
\text { 11. Courageous; willing to } \\
\text { challenge the status quo }\end{array}$ \\
\hline
\end{tabular}

$\mathrm{RFP}=$ request for proposal. 


\section{Validating the Competencies with Others}

To ensure that the content experts had identified competencies that were relevant to their colleagues, we used the competencies to develop a web-based questionnaire. The questionnaire consisting of 26 items and was distributed to all nursing leaders within the three partner organizations $(N=136)$. A modified tailored design method (Dillman 2007) was used for the design and electronic distribution of the invitation to participate, the link to the questionnaire and the reminder notices for study participants. Part 1 of the questionnaire asked participants to rate the relevance of each item to their role as a nursing leader, (not at all relevant to very relevant), with higher scores indicating higher degrees of relevance. Part 2 asked participants to rate their current level of confidence in their ability with each item. This provided information on nursing leaders' individual self-assessment and identified areas for professional development.

In total, 44 questionnaires (a 32\% response rate) were completed including representation from each of the three partner organizations. Survey results were analyzed using SPSS Version 16.0. Descriptive statistics were conducted for the items, as well as further analysis based on number of years of leadership experience. Demographics of the survey respondents revealed that the majority (59\%) had over 20 years' nursing experience and $50 \%$ had over 10 years' home healthcare sector experience. However, in their current leadership role, the majority (72\%) had five or less years' experience. This finding reinforces the need to provide supports for experienced nurses as they enter formal leadership roles and to not assume that years of clinical experience reflect the confidence and ability to assume leadership roles and accountabilities.

A content validity index (CVI) for the questionnaire was determined by calculating the proportion of responses where the rating for the item was scored as either quite relevant or very relevant (scores 3 or 4 on a 4-point Likert scale). The resulting CVI of 0.97 was higher than the minimum CVI of 0.80 described in the literature (Lynn 1986; Polit and Beck 2006). This finding confirmed that the items included in the questionnaire were relevant to the role of nursing leaders in the home healthcare sector.

Results of the self-assessment indicated that nursing leaders with less than five years' experience were the least confident in many of the competencies identified (e.g., managed care, human resources, quality indicators) when compared with responses from those with 10 years' experience or more in the sector (see Table 2). Although there were difference in the mean scores based on years of experience as a nursing leader, they were statistically significant in only three areas: understanding the managed care/request for proposal process $[t(42)=-2.07 ; p=.045]$, 
knowledge of ethical standards of practice $[t(42)=-2.11 ; p=.040]$ and knowledge regarding scope of practice issues in working with unregulated care providers $[t(42)=-2.18 ; p=.034]$. This information provided the foundation for the development of the ALIVE modules.

\section{Table 2. \\ Comparison of mean scores based on number of years of leadership experience, using a 4-point Likert scale: 1 (not at all confident) to 4 (very confident)}

\begin{tabular}{|c|c|c|}
\hline Competency & $\begin{array}{l}\text { Less than } 5 \text { years of } \\
\text { leadership experience } \\
\qquad N=32\end{array}$ & $\begin{array}{l}\text { Greater than } 5 \text { years of } \\
\text { leadership experience } \\
\qquad N=12\end{array}$ \\
\hline $\begin{array}{l}\text { Knowledge of community health nursing } \\
\text { standards }\end{array}$ & 2.75 & 2.92 \\
\hline $\begin{array}{l}\text { Understanding of the collective agreement } \\
\text { process and implications for practice }\end{array}$ & 2.45 & 2.58 \\
\hline $\begin{array}{l}\text { Understanding of the managed care process } \\
\text { (i.e., request for proposal process)* }\end{array}$ & 2.47 & 3.17 \\
\hline $\begin{array}{l}\text { Defining measures of quality and quality } \\
\text { indicators }\end{array}$ & 2.59 & 3.00 \\
\hline $\begin{array}{l}\text { Root cause analysis (i.e., differentiating } \\
\text { problems and the underlying causes of } \\
\text { issues) }\end{array}$ & 2.81 & 3.08 \\
\hline $\begin{array}{l}\text { The use of empowering strategies (i.e., } \\
\text { consultation, visioning, mutual problem } \\
\text { solving) to build capacity in others }\end{array}$ & 2.90 & 3.08 \\
\hline $\begin{array}{l}\text { Courage (i.e., willing to challenge the status } \\
\text { quo) }\end{array}$ & 2.91 & 2.83 \\
\hline $\begin{array}{l}\text { Knowledge of best practices (i.e., evidence } \\
\text { to support client care) }\end{array}$ & 2.91 & 3.27 \\
\hline $\begin{array}{l}\text { Time management skills; ability to manage } \\
\text { multiple priorities }\end{array}$ & 2.94 & 3.17 \\
\hline Use of technology (i.e., computer skills) & 2.94 & 2.92 \\
\hline Conflict management skills & 3.00 & 3.17 \\
\hline Knowledge of ethical standards of practice* & 3.03 & 3.50 \\
\hline $\begin{array}{l}\text { Knowledge regarding scope of practice } \\
\text { issues (i.e., working with unregulated care } \\
\text { providers)* }\end{array}$ & 3.06 & 3.58 \\
\hline $\begin{array}{l}\text { Negotiation skills (i.e., resolving conflicts, } \\
\text { reaching consensus) }\end{array}$ & 3.06 & 3.08 \\
\hline
\end{tabular}




\begin{tabular}{|c|c|c|}
\hline Competency & $\begin{array}{l}\text { Less than } 5 \text { years of } \\
\text { leadership experience } \\
\qquad N=32\end{array}$ & $\begin{array}{l}\text { Greater than } 5 \text { years of } \\
\text { leadership experience } \\
\qquad N=12\end{array}$ \\
\hline $\begin{array}{l}\text { Dealing with performance issues (i.e., } \\
\text { supervising others; supervising "peers") }\end{array}$ & 3.09 & 3.50 \\
\hline $\begin{array}{l}\text { Leadership skills (i.e., the ability to lead, } \\
\text { motivate others, achieve desired outcomes) }\end{array}$ & 3.12 & 3.17 \\
\hline $\begin{array}{l}\text { Providing constructive feedback to others } \\
\text { (i.e., staff and peers) }\end{array}$ & 3.13 & 3.25 \\
\hline $\begin{array}{l}\text { Ability to adapt to external environment (i.e., } \\
\text { takes initiative, innovative) }\end{array}$ & 3.16 & 3.08 \\
\hline $\begin{array}{l}\text { Consistency (i.e., transparent in decision- } \\
\text { making, follow-through) }\end{array}$ & 3.16 & 3.25 \\
\hline $\begin{array}{l}\text { Emotional intelligence (i.e., awareness of } \\
\text { personal emotions and impact on others) }\end{array}$ & 3.22 & 3.33 \\
\hline $\begin{array}{l}\text { Sense of engagement (i.e., being genuinely } \\
\text { present, enthusiasm ) }\end{array}$ & $3 \cdot 30$ & 3.17 \\
\hline $\begin{array}{l}\text { Effective listening communication skills (i.e., } \\
\text { when communicating with others primarily } \\
\text { via email/phone) }\end{array}$ & $3 \cdot 31$ & 3.42 \\
\hline $\begin{array}{l}\text { Being accessible (face-to-face and/or } \\
\text { "virtually") }\end{array}$ & $3 \cdot 34$ & 3.50 \\
\hline $\begin{array}{l}\text { Knowledge regarding confidentiality } \\
\text { (i.e., relevant legislation regarding } \\
\text { communication of client information via } \\
\text { email/fax/phone) }\end{array}$ & $3 \cdot 37$ & 3.58 \\
\hline $\begin{array}{l}\text { Establishing the agency's good reputation } \\
\text { within the professional and lay community }\end{array}$ & 3.45 & 3.67 \\
\hline Ability to demonstrate caring for others & 3.47 & 3.67 \\
\hline
\end{tabular}

* Differences are statistically significant, $p=<.05$.

\section{Phase 2: Development of the ALIVE Pilot Program}

The top 10 areas identified for development through the self-assessment results included:

1. Understanding labour management practices

2. Understanding the managed competition process

3. Defining measures of quality and quality indicators

4. Knowledge of community health nursing standards

5. Root cause analysis 
6. Use of technology

7. Conflict management

8. Time management

9. Courage

10. Knowledge of best practices

Based on needs revealed in the self-assessment results, four modules were identified for inclusion in the pilot offering of the ALIVE Community Nursing Leadership program. Specific to the home healthcare sector and the role of nursing leaders in that sector, these initial modules were (1) managed competition, (2) quality indicators: development and use (incorporating content for defining measures of quality and quality indicators with root cause analysis), (3) dealing with performance practices, and (4) managing multiple stakeholders (incorporating principles of conflict management into dealing with multiple stakeholders).

The pilot program was designed to be delivered in two sessions. Session 1 spanned two consecutive days (November 2008); Session 2 was a one-day follow-up held two months later (January 2009). The modules were initially designed in a faceto-face format in order to effectively test the content and obtain feedback from participants. Sixteen nursing leaders from the three partner organizations were chosen to participate in the pilot offering. Twelve of these had also been involved in the content-expert panel exercise in May 2008. To obtain a totally fresh perspective on the module content, four additional nurse leaders representing the three partner organizations were invited to participate and provide feedback.

To reinforce the value of inter-organizational collaboration, internal content experts, from each of the partner organizations were identified and invited to participate in the design, content development and actual delivery of the program modules. This resulted in collaboration between departments, organizations and roles (e.g., business development, quality, education and human resources), internally within the organizations and across the partners, thus contributing to the richness of the information presented.

Pilot Program Evaluation Results

Upon completion of Phase 1 of the pilot program, participants were asked to complete a web-based survey. The survey consisted of open-ended questions aimed at obtaining feedback on which aspects of the module content were most or least helpful, how applicable the content was to their role and suggestions for improvement. Results indicated a high level of satisfaction with the content and application to their role as nursing leaders. 
Feedback included comments such as:

The overall presentation was very informative and complete. Even though I have been involved with a number of RFPs, there were things I picked up.

All of it was helpful. It's just a matter of accessing the information when needed. I also like the idea of collaborating with other "agency mates" who may have experience in dealing with similar situations.

... suggest that all new managers have this training within a few months of hire.

Additional feedback was obtained through roundtable discussions to gain the pilot program participants' perspectives on the benefits of the program as it relates to retention of nursing leaders and suggestions for sustainability.

Two themes emerged from the discussions:

- The importance of networking. The value of coming together as a group of nursing leaders was consistently described as a positive aspect of the program and a contributing factor to participants' renewed energy for their leadership role. In comparison with the acute care sector, nursing leaders in home healthcare often function in isolation, with the additional barrier to collaboration and networking of being in competition with others. The ability to convene for a common purpose (e.g., participants' learning and development) was described as being very energizing and beneficial. A specific comment about the impact on retention was the realization that " $\ldots$ all of us that have been involved with this program from the beginning are still here seven months later ... without losing anyone ... that says something about the benefit of the program."

- Knowledge to support the role. Participants identified information shared in the modules as beneficial to their role as nursing leaders. Although all received some type of initial orientation, most found it quite limited. By having access to information that was specifically geared to their role and their sector, participants' ability to apply the knowledge in their day-to-day practice was greatly enhanced. This in turn had a positive impact on self-confidence in their role, as evidenced by the following comments:

The information we discussed in the program gave me the confidence to go back and find out more.

There is no one to mentor you on a regular basis, so this information is vital to any new leader. 


\section{Phase 3: Implementation of the Web-Based Program}

To build on the success of the pilot program and to enable wider access to the content by all nursing leaders, the modules were developed into web-based content, complete with audio and visual components. The original presenters again volunteered their time to audiotape their presentations as separate modules that would be hosted on the Ontario Community Support Association (OCSA) website, within the members-only section, and available to all OCSA member organizations. Module design allows access to the materials at any time and from any location. Participants can pause the audio/video and restart or go back to specific content areas without having to view the entire module. Slide presentation materials and other documents are posted with each module to accompany the audio presentation. (See Figure 2 for a screen shot of the module.)

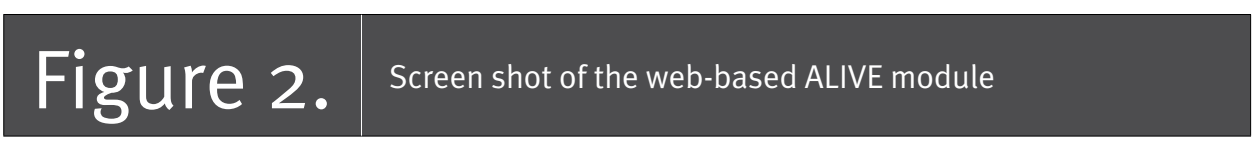

\section{ALIVE Project}

Module 1: Managed Competition

Module 1 | Module 2 | Module 3

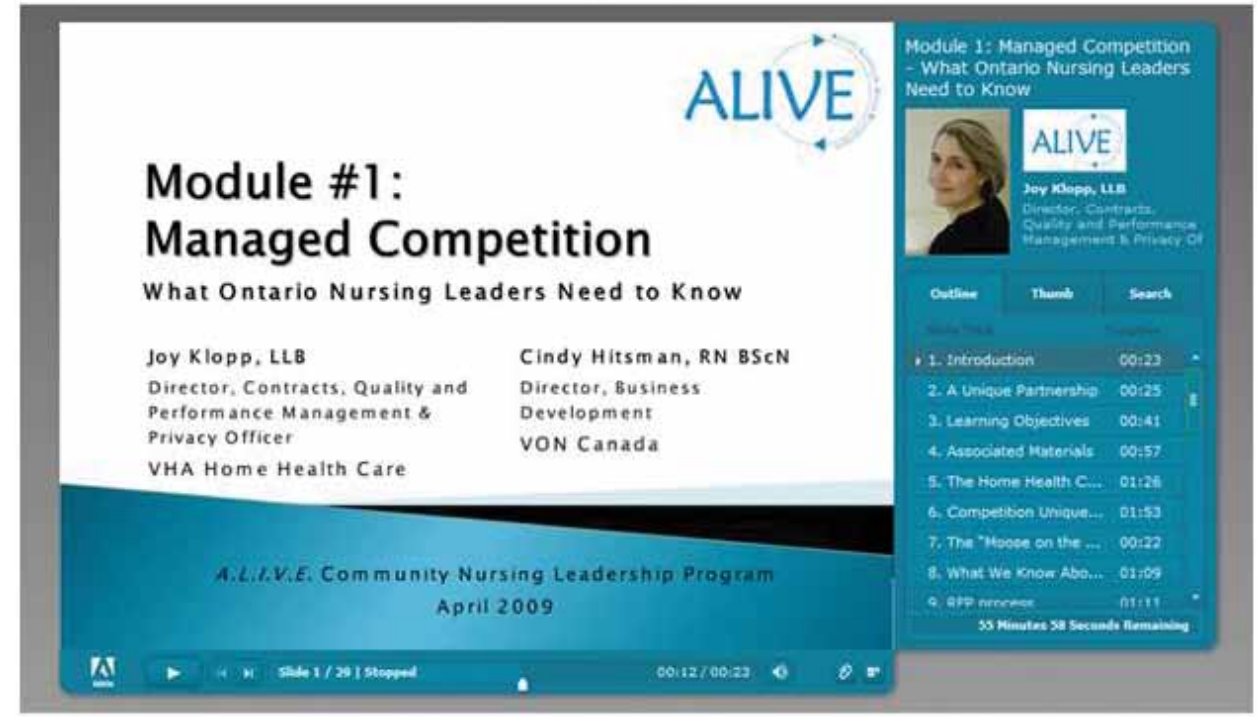

Participants who view the modules are asked to complete a short quiz to demonstrate their understanding of the content. They can then print a "certificate of completion" that may be used toward organizational performance reviews and/or reflective practice requirements for the College of Nurses of Ontario. Initial feedback has been very positive regarding areas such as: ease of access, relevant content and clear audio, all contributing to a valuable learning resource. 


\section{Plans for Sustainability}

Despite the challenge of procuring ongoing funding, steps have been taken to ensure sustainability of the program. They include:

- The OCSA Nursing Committee will oversee the ALIVE web-based modules. Four members of the ALIVE advisory group sit on OCSA committee, allowing for continuity and follow-through. This group will be responsible for identifying changes required to existing modules and for addition of new modules and content, as well as for monitoring overall utilization, evaluation results and feedback.

- Future educational offerings via conference calls will link nursing leaders together from the three partner organizations, allowing for optimal participation across the province. OCSA Nursing Committee members will assume the lead in organizing these sessions, as well as determine content and facilitation. Formats may include presenting challenging cases, sharing best practices and strategies for keeping self and staff "engaged" when working in a virtual environment.

- Webinar presentations will share information about the project with other home healthcare organizations, including results from the pilot program, and will market the ability to access the modules online.

- The ALIVE web-based modules will be part of orientation for all new leaders nursing and other leadership roles.

\section{Results}

As demonstrated by the results described above, the ALIVE Community Nursing Leadership program was a huge success. The benefits have extended beyond the nursing leaders who participated in the program to others who are aware of the investment their organization has made in the program. Comments from pilot participants indicate that their colleagues are looking forward to the outcomes of the pilot project and the opportunity to benefit from the content. The ability to access the web-based resource, whenever and wherever convenient for the user, will help to facilitate learning needs and professional development of nursing leaders across the organizations.

The partnership between Saint Elizabeth Health Care, VON Canada and VHA Home HealthCare has demonstrated the benefits of inter-organizational collaboration toward a common goal. It has forged new relationships and shared learning across these organizations, despite their being in competition with one another for the ability to provide home healthcare services. The common desire to invest in development and retention of nursing lead- 
ership enabled a creative approach to program design, implementation and sharing of resources.

Evaluation results provide insight into not only the learning needs of home healthcare sector nursing leaders, but also on the importance of opportunities for shared dialogue, networking and "communities of practice" for leaders who often work in isolation.

Although the results of the pilot program can be applied only to the nursing leaders from the three participating organizations, the processes utilized to create the ALIVE program can easily be applied to other sectors and professional roles or interprofessional groups.

\section{Acknowledgements}

Despite the success of the partnerships and the enthusiasm of the ALIVE pilot participants, this program would not have been possible without the funding support from the Nursing Secretariat of Ontario's Ministry of Health and LongTerm Care, and HealthForceOntario. The ability to bring together representatives from the various organizations, tap into our content experts and enable the time and space for the nursing leaders to come together has been invaluable to the overall success of this program.

We would also like to acknowledge the Ontario Community Support Association (OCSA) for their support throughout the project and for providing a "home" for the ALIVE web-based modules on the OCSA website.

Lastly, we would like to acknowledge the 16 nursing leaders who were not only our content experts and our pilot participants, but also our source of inspiration throughout the entire project! Their dedication to providing excellent patient care and a quality work environment for staff is truly remarkable.

$\begin{array}{lll}\text { Liz Loftus } & \text { Grace Zadworna } & \text { Neriza Neville } \\ \text { Alana Scichilone } & \text { Colleen Turner } & \text { Denise Lywood } \\ \text { Catherine Legault } & \text { Kathy Desautels } & \text { Mary Aubin Cadet } \\ \text { Mike Young } & \text { Ann Gowie } & \text { Richard Rementilla } \\ \text { Heather Cooke } & \text { Kathy Craddock } & \text { Susan Watson } \\ \text { Stacey Graham } & & \end{array}$

Correspondence may be directed to: Sherri Huckstep, Executive Director Operations \&Chief of Practice, VON Canada, Central Region, sherri.huckstep@von.ca. 


\section{References}

Armstrong-Stassen, M. and S. Cameron. 2005. "Concerns, Satisfaction and Retention of Canadian Community Health Nurses." Journal of Community Health Nursing 22(4): 181-94.

College of Nurses of Ontario 2002. Professional Standards. Retrieved March 4, 2008. <http://www. cno.org/docs/prac/41006_ProfStds.pdf>.

Community Health Nurses Association of Canada 2003. Canadian Community Health Nursing Standards of Practice. Retrieved March 4, 2008. <http://www.chnc.ca/documents/chn_standards_of_ practice_mar08_english.pdf>.

Dillman, DA. 2007. Mail and Telephone Surveys: The Tailored Design Method. 2nd Edition. New York: John Wiley \& Sons.

Flynn, L. and J. Deatrick. 2003. "Home Care Nurses' Descriptions of Important Agency Attributes." Journal of Nursing Scholarship 35(4): 385-90.

Fraser, S.C. 2003. "Magnet Home Care Agency Characteristics: A Professional Way to Impact Quality and Retention." Home Healthcare Nurse 21(9): 603-10.

Hood, J. and H. Smith. 1994. "Quality of Work Life in Home Care: The Contribution of Leaders' Personal Concern for Staff." Journal of Nursing Administration 24(1): 40-7.

Kramer, M. and C. Schmalenberg. 1988a. "Magnet Hospitals: Part I. Institutions of Excellence.” Journal of Nursing Administration 18(1): 13-24.

Kramer, M. and C. Schmalenberg. 1988b. "Magnet Hospitals: Part II. Institutions of Excellence." Journal of Nursing Administration 18(2): 11-9.

Lynn, M. 1986. "Determination and Quantification of Content Validity." Nursing Research 35(6): $382-5$.

Mackoff, B. and P. Triolo. 2008. "Why Do Nurse Managers Stay? Building a Model of Engagement. Part 1, Dimensions of Engagement." Journal of Nursing Administration 38(3): 118-24.

O’Neil, E., R. Morjikian, D. Cherner, C. Hirschkorn and T. West. 2008. “Developing Nursing Leaders: An Overview of Trends and Programs." Journal of Nursing Administration 38(4): 178-83.

Polit, D. and C. Beck. 2006. “The Content Validity Index: Are You Sure You Know What's Being Reported? Critique and Recommendations." Research in Nursing and Health 29(5): 489-97.

Smith, C. 1997. "Home Health Care Leadership in a Changing Environment." Home Health Care Management Practice 9(6): 38-44.

Smith-Stoner, M. 2004. "Home Care Nurses' Perceptions of Agency and Supervisory Characteristics: Working in the Rain." Home Healthcare Nurse 22(8): 536-46.

Zurmehly, J. 2007. "A Qualitative Case Study Review of Role Transition in Community Nursing." Nursing Forum 42(4): 162-70. 